\title{
An Assessment of the Impacts of Institutional Intervention on the Livelihood of Orphan and Vulnerable Children: The Case of ECC-SDCOH, Dire Dawa Administration, Ethiopian
}

\author{
Takele Bekele Bayu \\ Department of Pedagogy and Morality, Dire Dawa University, Dire Dawa, Ethiopia \\ Email address: \\ takebek1983@yahoo.com \\ To cite this article: \\ Takele Bekele Bayu. An Assessment of the Impacts of Institutional Intervention on the Livelihood of Orphan and Vulnerable Children: The \\ Case of ECC-SDCOH, Dire Dawa Administration, Ethiopian. Humanities and Social Sciences. Vol. 5, No. 3, 2017, pp. 113-120. \\ doi: $10.11648 /$ j.hss.20170503.11
}

Received: January 30, 2017; Accepted: February 27, 2017; Published: May 27, 2017

\begin{abstract}
In line with the government's poverty reduction strategy program, Ethiopian Catholic Church (ECC) Social Rehabilitation Strategy and ECC- Social and Development Coordinating Office of Harar (ECC-SDCOH), in partnership with Secours Catholique/Caritas France and DKA Austria, has implemented community Based Orphan and Vulnerable Children Prevention and Rehabilitation Projects in Kebele 02, Kebele 06 and Kebele 04 of Dire dawa administration with the objective to improve the social, economic and psychological situation of Orphan and Vulnerable Children living in the community with special emphasis to children of the street. This particular study has been conducted with the objective to investigate and analyze the impacts of social and capacity building service provision as well as project implementation experiences focusing on the life and livelihood (social, economic and psychological situation) of Orphan and Vulnerable Children living in the community with special emphasis to children of the street in order to identify, value and document success and failure stories thereby to scale up and better design future intervention; implementation strategies and service provision approach. In view of this, the study has purposefully selected sample group and conducted intensive discussion with targeted OVC; parents/guardians of targeted OVC; Community based organization (CBOs); governmental and non-governmental organizations, private firm owners, community representatives, and school communities with the view to generate primary information about the project and its impacts on the beneficiaries. Besides, the project has analyzed secondary documents such as project proposal, project terminal report, and other associated documents. The information gathered from the aforementioned sources has revealed that the project has significantly improved the social, economic and psychological situation of targeted Orphan and Vulnerable Children and their families. However, the study has also identified and documented certain limitation in the process of project implementation and management. In conclusion, this particular study has recommended that the work of ECC- SDCOH can be used as a model and hence be reproducible in future interventions for OVC in different localities.
\end{abstract}

Keywords: Orphan, Vulnerable, Livelihood, Improvement, Of Street, On Street, Children

\section{Introduction}

For an organization to progress and adapt to change, it must become a learning organization which draws lessons from its experiences in order to identify and understand good practices." 1 These good practices will improve the way the

1 Good Practices at FAO: Experience capitalization for continuous learning, External Concept note September, 2013 organization works. They can be applied to specific contexts, institutionalized, shared and replicated at different levels: from local to international. However, if no action is taken to analyze, capitalize and share the knowledge gained in programmes and projects, institutional memory will not be transmitted, the same mistakes will be repeated, the success of project experiences will not be known and opportunities 
for improved practices will be lost, thereby prevent the sharing of good practices. An organization can turn knowledge into action through knowledge sharing and capitalization of experiences.

Therefore, the main purpose of this particular study was to assess ECC-SDCOH's project implementation and analyze its impacts on the life and livelihood of orphan \& vulnerable children and their families. Besides, the study aims at experience capitalization by documented ECC-SDCOH' projects experience (with its success and failure) to the end improve the institution's capacity and future practices. Further, the output of this study helps others institutions working on the area of orphan and vulnerable children to consider fundamental issues in OVC project implementation.

Focus Theme

a. The geographic area for this particular study were Kebele 02 (Gindetesfa area), kebele 06 and 04 of Dire Dawa administration

b. This particular project has addressed as many beneficiaries as possible and has established evidence as to whether the supports given by the projects were appropriate, sufficient, effective, and complete to address and solve their personal, social and economic problems.

c. In the process of implementing the project, communication with various governmental and nongovernmental stakeholders and other partners in both localities has been established to identify and confirm their realistic roles in the future project or program implementations.

d. This particular study has documented the success and failure of the project implementation. and provided clear insight to enhance its future performance.

\section{Brief Description of the Research Project Method Used}

Since the objective of this study was to analyze project implementation experiences on the provision of social and capacity building service, the project has used exploration design which urges the need to conduct in-depth discussion and understanding on the overall issues of the project with beneficiaries; CBOs; relevant project participants and stakeholders. Accordingly, the project has attempted to collect and organize information about the experience from project documents and the other actors. In effect, the project has utilized qualitative information/data and their results analyzed qualitatively and simple descriptive statistics i.e., percentage distributions was used to analyze quantitative data.

\subsection{Data Sources and Instruments of Data Collection}

a. Sources of data:- the study has used two sources of data

1. Primary sources of data: -primary data has been collected from the identified and prioritized actors who participated directly in the project. These were beneficiaries and actors involved in the decision making process of the experience which includes targeted children, caregivers, CBOs and Kebele administration, women, children and youth office, Labour and social affairs office, Bureau of economic and finance, SOS, Cooperative promotion office have been selected purposefully. They also include targeted OVC; parents and guardians of targeted OVC, voluntary social workers; CBOs representatives", concerned governmental offices and bureaus, NGOs and Private firm owners. Similarly, since the study was dealing with larger groups of people, the project purposefully has selected representatives from those actors directly involved in project implementation and management process given gender equality, role in the experience, availability to participate in the interview/workshop, leadership status within the group and others. Accordingly, the project has conducted:-

a. Interview with representative beneficiaries;

b. Group workshop to reconstruct the experience;

c. Group workshop to identify lessons learned and best practices and

d. Internal team meeting to consolidate and organize the results.

1. These sources have guaranteed the study to collect and organize qualitative information using different methods of data collection, i.e. key informant interview, Focus Group Discussion (FGD) and Observation Method.

b. Secondary sources of data: - the study has reviewed various types of documents including project proposal, Monitoring documents, project evaluations, progress reports, project terminal report, and other relevant project documents from ECC-SDCOH.

\subsection{Methods of Data Analysis}

a. Combinations of both qualitative and quantitative methods have been employed as a summary of data analysis process for the quantitative and qualitative data. The quantitative data has analyzed to address the research questions. In effect, the study used primarily simple descriptive statistics i.e., percentage distributions.

b. On the other hand, the study has made use of thematic and content based analysis in describing and interpreting the qualitative data. Hence, all data gathered using key informant interview (KII); Focus Group Discussion (FGD); Observation Method has been analyzed qualitatively through narration.

c. Finally, secondary data gathered from project proposal, annual and terminal project report; progress reports as well as publication and other sources of published information from ECC-SDCOH have been carefully scrutinized and analyzed to secure their reliability; suitability and adequacy. 


\section{Results and Discussion}

a. To contribute for the efforts made by the government in addressing the ever-increasing problem of Orphan \& Vulnerable Children, the role of community and welfare organizations are indispensible. In line with this, ECCSDCOH with a support from its international partners, SCCF (Secours Catholique Caritas France) and DKA Austria (Dreikönigsaktion), has designed and implemented a community based OVC prevention and rehabilitation project with the view to address the socioeconomic problems of OVC and ensure self-reliance.

b. The group discussion and key informant interview conducted with project staffs, CBOs representatives', relevant local and regional government representatives and the project terminal report document has indicated that ECC-SDCOH has adopted participatory approach as a major strategy for the implementation of the proposed project while facilitating capacity building and empowerment program for CBO's, project staffs and voluntary social workers to enable them permanently provide project services for OVC through the mobilization of local resources.

1. However, there have been awareness problems amongst the various structure of government and community in relation to the issues and problems of OVC. In this regard, ECC-SDCOH has provided knowledge-based advocacy and lobby thereby policy makers and local governments and community at large were able to take practical responses and actions on the issues and problems of OVC. In effect, the project management body together with community project management supporting committee has made dialogue with local government administration and private institutions which paved the way to access to health and education services to targeted OVC as part of their basic right.

This particular study identified that the ECC-SDCOH project has provided various social 1, economic and psychological as well as capacity building services for orphan and vulnerable children and their families in the study area. Accordingly,

A.ECC-SDCOH has constructed/renovated the social center in order to permanently deliver the various social and capacity building services to targeted OVC and their families.

a. The issue of the social centre has been one of the key issues for the project management supporting committees as well as for the project staff in the process of project implementation and management. $\mathrm{n}$ this regard, ECC-SDCOH has organized Community project management supporting committee; selecting members from local level government administration and structure, local community representatives and $\mathrm{CBO}$ representatives, who have made intense discussion and negotiation with diverse concerned government structure to solve the issue of drop-in centre. b. In effect, ECC-SDCOH has constructed/renovated the social centre and equipped the center with various equipment, materials and facilities in order to facilitate and provide educational, health, psycho-social and capacity building services to all targeted OVC and their families at each project of a kebele while being in their respective localities.

1. Accordingly, in kebele 02 ECC-SDCOH has used the drop-in center owned by Hararghe Catholic Church found in the village in the provision of services.

2. In kebele 04, the local government has provided ECC-SDCOH with health center and the project has renovated the drop-in center thereby provided various services.

3. In kebele 06, ECC-SDCOH, after intense negotiation with kebele officials has received a plot of land thereby constructed a new drop-in center and provided diverse services to targeted OVC based in the social center.

c. Therefore, the renovation /construction of the social center has played irreplaceable role in the provision of holistic support and in effect, has played big role in the smooth implementation and management of the project. Further, the social center at each project of a kebele helped ECC-SDCOH not only to realize the very objectives of the project but also guaranteed service sustainability.

B. ECC-SDCOH has provided diverse social services to all targeted OVC and their families.

i. Access to Education

a. The information from the focus group discussion and key informant interview with CBOs representatives'; caregivers, beneficiary children, school principals and teachers, local kebele administration and their structure, relevant government and non-government organizations representatives and private group representatives as well as the project terminal report document have all confirmed that "ECC-SDCOH has targeted both "off street children" and "on street children" with diverse socio economic problems and thereby integrated them in formal education system".

1. As part of the school intervention, the project has mobilized volunteer teachers from the community, provided targeted OVC's with "stationery materials, uniform, payment of monthly school fee for night time students, tutorial services and library service.

2. Therefore, due to the intervention targeted OVC have attended their education regularly, have been promoted to the next grade and their academic performance (in terms of their rank in the class) has been improved as indicated in the following parameters".

3. Out of 150 targeted OVC from kebele 02 project:-

a) $93 \%$ of target children have attended their formal education during day or night time;

b) $87 \%$ of target children who made to attend formal school promoted to the next grade; 
c) $89 \%$ of targets' academic performances (in terms of their rank in the class) have improved compared to baseline survey data.

4. Out of 300 targeted OVC from kebele 04 project:-

a) $90 \%$ of target children have attended their formal education during day or night time;

b) $90 \%$ of target children who made to attend formal school promoted to the next grade;

c) $90 \%$ of targets' academic performances (in terms of their rank in the class) have improved compared to baseline survey data.

5. Out of 333 targeted OVC from kebele 06 project,:-

a) $98 \%$ of targeted children have attended their formal education during day or night time;

b) $90 \%$ of targeted children who were involved in formal school promoted to the next grade;

c) $90 \%$ of targets' academic performances (in terms of their rank in the class) have improved compared to baseline survey data.

However, Due to shortage of capital the project has provided scholastic materials once in a year which in turn affected the learning process of targets OVC. Like shortage of exercise book, which negatively affected children learning process, has been reported in the group discussion with beneficiary children and their care givers as well as CBOs representatives', since it was given to targeted children once in a year.

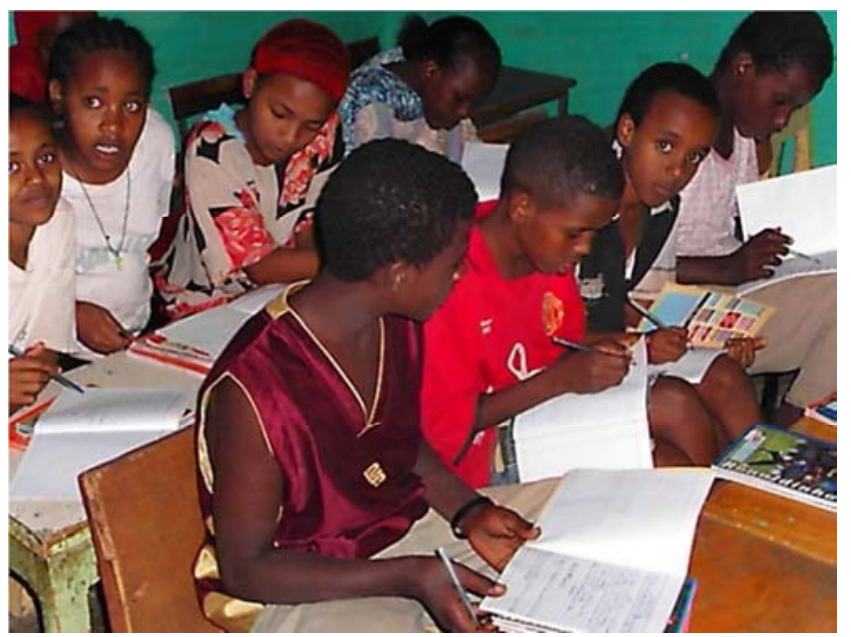

Figure 1. Target Children attending tutorial class.

ii. Psychosocial support

a. As a result of the deep rooted social and economic problem in the community in general and families in particular, targets orphan and vulnerable children suffered from various psycho-social problems. In this regard, ECC-SDCOH aims to alleviate the deep rooted psycho-social problems has provided guidance and counseling services for all targeted children in each project site based on their status and needs using techniques and approaches including child to child peer, individual and group counseling, adult role models or "mentors", facilitating indoor and outdoor games, holiday celebration and organizing life skill training.
1. For instance, out of 300 targeted OVC from kebele 04:-

a) $90 \%$ of targeted children have explained that they are happy with life;

b) $80 \%$ of target children were participated in various social and recreational activities;

c) $90 \%$ of the target children have received class on child rights and

d) $70 \%$ of target children came to the drop-in center and participated in recreation activity spending at least 90 minutes in a week during the project period.

b. Therefore, this capitalization experience has indicated that the project has improved the psychosocial well-being of targeted children and brought significant changes in their behavior and attitude as expressed in school attendance, participation in games and play, relationship with their family, project staff and the community.

c. However, the group discussion with beneficiaries and CBOs representatives' has revealed that the psychosocial support was not guided by professional personnel. If it was conducted in this way, the project would observe much more change on the behavior and attitude of target children.

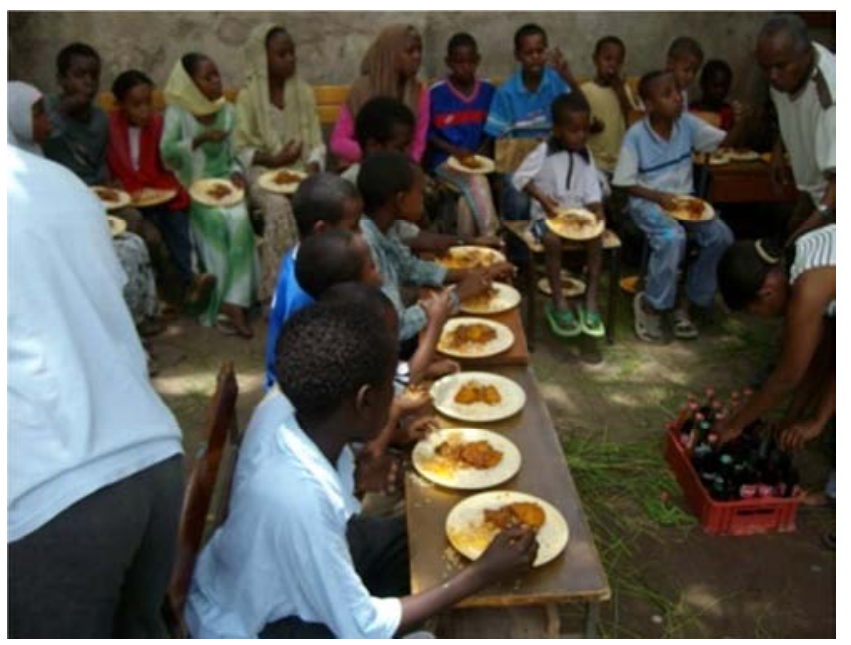

Figure 2. Children celebrating new-year in the social center.

iii. Access to medical treatment and health education;

a. Most OVC particularly street children have suffered from different health problems due to several reasons. To mitigate the health problem of targeted children the project has provided preventive health and medical service for all targeted OVC in their respective project site. In the provision of curative treatment, the project was involved in a contractual agreement with government and private health institutions. In effect, the timely provision of medical treatment has benefited targeted OVC in a way that it reduced the number of days children absent from their school as well as further saved them from life threatening complications. Besides, the children were prevented from taking harmful traditional medicines that has adverse effect on 
their health.

b. The project has also taken various activities as part of the preventive health services including procurement of soap, facilitation of shower and laundry service and awareness creation and educational programs and workshops on health issues. In effect, the project has improved the personal and environmental hygiene of targeted OVC and their understanding on HIV AIDS transmission and prevention, family planning and reproductive health has been increased.

c. Accordingly, out of 150 targeted OVC from kebele 02 project:-

1. an average $83 \%$ targeted children benefitted from the curative medical service;

2. 97\% targeted children were provided soap and shower services and benefited from preventive health education service during the project period.

d. Out of 300 targeted OVC in kebele 04 project:-

1. $90 \%$ of sick target children received diagnosis and treatment service;

2. $80 \%$ of target children know how on preventive diseases, environmental and personal hygiene, communicable diseases and reproductive health (including HIV/AIDS) and measures to be taken and

3. $95 \%$ of target children received soap for personal hygiene and $60 \%$ of them took shower at least once in 15 days during the project period.

e. Out of 300 targeted OVC from kebele 04 project:-

1. an average $73 \%$ targeted children benefitted from the curative medical service;

2. $100 \%$ targeted children were provided soap and shower services and benefited from preventive health education service during the project period.

However, as revealed in the group discussion with beneficiaries and CBOs representatives', if the project hires professional health workers, then it would easily coordinate and facilitate the health services to target beneficiaries.

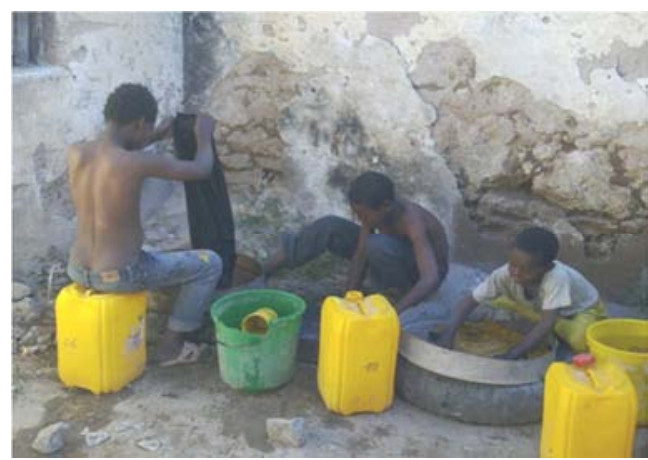

Figure 3. Children of the street washing their clothes.

ECC-SDCOH has provided capacity building services for CBOs, voluntary social workers, targeted OVC and their families.

i. ECC-SDCOH has empowered the capacity of CBOs and voluntary social workers to assure project sustainability. a. The project has facilitated and organized field visit and capacity building training/ support for community project management supporting committee and CBOs with the view to learn best practices as well as to improve their knowledge of the issues and problems of OVC; participation skill and knowledge as well as their experiences. In effect, CBOs and community project management supporting committee have been capacitated and empowered and actively involved in the process of project design and implementation.

b. As part of project sustainability program, ECC$\mathrm{SDCOH}$ in collaboration with local government administration and local community representatives has selected, organized, empowered and finally legalized model community structures/organizations as service provider, given their experience, commitment and dedication in community based development activities, and provided diverse capacity building training to help better manage project activities after its termination.

c. Accordingly, Kebele 02 has yet not handover;

d. Kebele 04 Mebrat Haile MeredajaIddir, a community based organization that has been empowered to take over kebele 04 OVC support project;

e. Raey Children Support Society (RCSS), a community based organization that has been empowered to take over Kebele 06 OVC support project.

ii. ECC-SDCOH has provided vocational skill training for targeted OVC

a. Provision of marketable training for targeted vulnerable children believed to have a paramount importance to broaden employment opportunity thereby to tackle their economic problems. Knowing this, ECC-SDCOH has organized and facilitated training on practical/vocational skills to support physically and mentally matured targeted OVC. In this regard, the project has communicated with various private firms in order to guarantee free on field training in areas such as wood and metal works, vehicle maintenance, hair dressing and driving license.

b. In the process of facilitating training, ECC-SDCOH has provided various supports including psychosocial, pocket money, safety equipment like eyeglass, work clothes and safety shoe, and feeding services for targeted OVC. These efforts have helped in keeping and sustaining skill trainees in the training.

c. Accordingly, from kebele 02 project 15 (11 male and 4 female) physically and mentally matured targeted OVC's received vocational skill training and employment opportunity thereby able to generate better monthly income that ranges from 370.00 to 2500.00 birr which has supported them to sustain a good life. 
d. from kebele 04 project, 80 (66 male and 14 female) targeted OVC were involved; in wood work (52), Metal work (4), Auto mechanic (4) and hair dressing (12) Driving License (8) and $85 \%$ has got employment opportunities getting monthly salary that ranges from 370.00 to 2500.00 birr and become selfreliant.

e. from kebele 06 project 98 ( 80 male and 18 female) targeted OVC were involved; in wood work (48), Metal work (12), Auto mechanic (2) and hair dressing (36) and 98\% has got employment opportunities getting monthly salary that ranges from 350.00 to 2000.00 Birr and became self-reliant.

However, the discussion held with beneficiary children and $\mathrm{CBOs}$ representatives has indicated that some of the target trainees have had dropped out from the training, particularly female trainees. Reasons for dropout from the training were identified as change of resident place, marriage, lack of diversification in skill training options, weak psycho social support and looking for employment to family livelihood. If the project provided various skill training options and facilitated professionally guided counselling and guidance the number of drop out could have been insignificant.

a. Therefore, future projects shall consider options like mobile maintenance; electricity, waitress, and others given the market opportunities shall be accessed to targeted OVC. This could guarantee targets children to choose the kind of skill areas in their demand/interest and which in turn plays an important role to sustain trainees on the training and tap market opportunities.

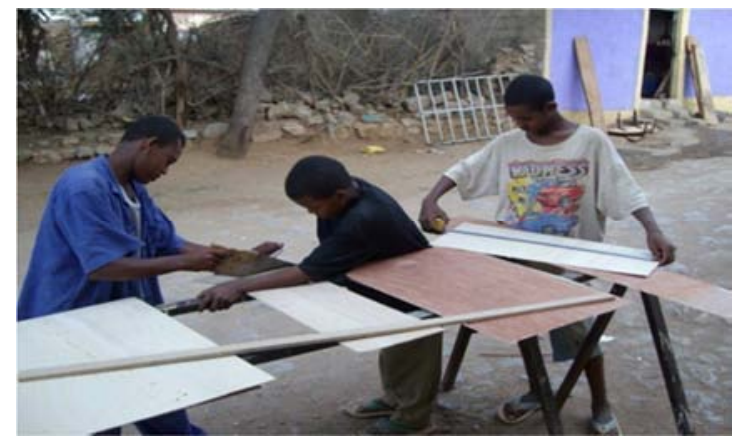

Figure 4. Children participating in skill training.

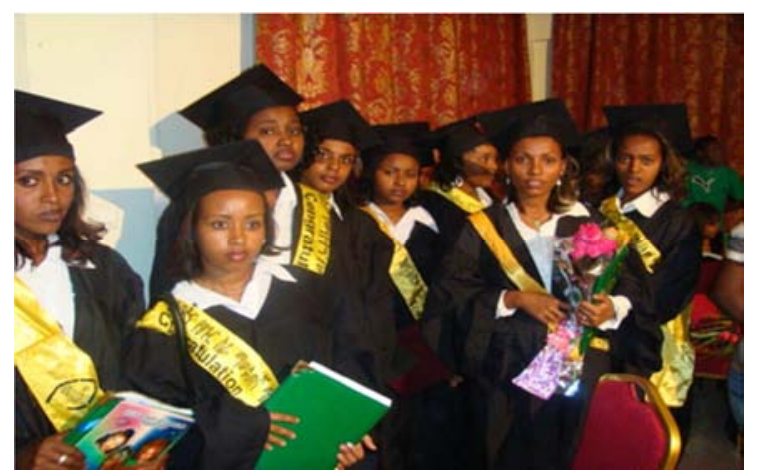

Figure 5. Hair dressing trainees on their graduation day. iii. ECC-SDCOH has provided revolving credit services for caregivers

a. Supporting care in community with revolving credit to improve the livelihood of targeted children parents/guardians was among the major planned capacity building activities of the project. In this regard, the parent/guardians of the targeted children who have an interest to participate in income generating activities (IGA) were organized and formed credit and saving cooperatives. In effect, ECC-SDCOH has provided revolving credit services and facilitated, in partnership with stakeholders, business related capacity building trainings. This has helped caregivers to engage in various income generating activities including selling of fruits and vegetables; selling of local brew; selling of street food; selling of wood charcoal; preparing and selling local bread; goat rearing and others.

1. Accordingly, from Kebele 02 project 50 caregivers ( 15 male and 35 female) have been organized in saving and credit cooperatives and have benefited from the project.

2. From Kebele 04 project, 118 caregivers ( 2 male and 116 female) have been organized in saving and credit cooperatives under the name of "EdigetLehitsanat Saving and Credit Cooperative" and have benefited from the project.

3. From Kebele 06 project, 135 caregivers (48 male and 87 female) have been organized in the name of Serto Madeg Bemillenium Credit and Saving Association and have benefited from the project.

b. The project has identified some of the income generating activities and helped microcredit beneficiary parents/guardians to engage in:-

1. selling of fruits and vegetables;

2. selling of local brew;

3. selling of street food;

4. selling of charcoal;

5. preparing and selling injera (Local Bread);

6. goat rearing and others.

c. Hence, through the provision of saving and credit services, the project has assured that households caring for vulnerable children have sufficient income to care for their children.

1. However, unlike the terminal project report, the group discussion held with beneficiary parents, various stakeholders as well as project implementing committee has revealed that some parents/guardians of target OVC who received credit services from the project has not been used the money for the intended purpose. Likewise, some of those who used the credit for the intended purpose, despite improvements in their livelihood, they were not in a state of providing the needed support for their child. This is against the intention of the project since parents/guardians who received credit from the project were expected to improve their life and thereby provides the necessary 
support for their children while substituting the project.

d. Therefore, before the provision of credit services, intensive awareness raising program found paramount important. The provision of credit services was also limited in the sense that the capital was small to support parents/guardians of target OVC in IGAs as well as some of them were targeted. Beside, early follow up and employing strict monitoring and evaluation activities could ensure beneficiaries to use the money for the intended purpose.

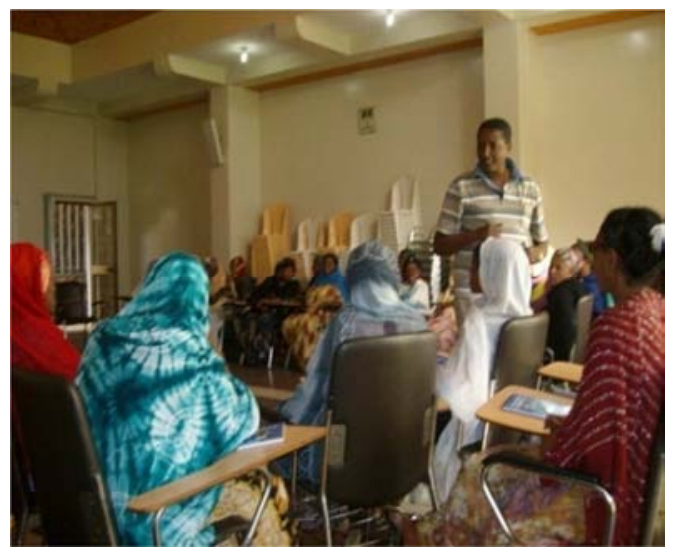

Figure 6. Parents of OVC taking Training on Microcredit and saving.

\section{Conclusion}

a. ECC-SDCOH's project on orphan and vulnerable children prevention and rehabilitation project has been implemented and benefited 150 OVC, 300 OVC, 333 OVC from kebele 02 (Ginde Tesfa Village), Kebele 04 and kebele 06 respectively in Dire Dawa administration.

b. ECC-SDCOH has adopted participatory approach as a major strategy for the implementation of the proposed project while facilitating capacity building and empowerment program for CBO's and voluntary social workers to enable them permanently provide project services for OVC through the mobilization of local resources.

c. Based on the information obtained from the major actors like beneficiaries children, parents/guardians of OVC, CBOs representatives'; relevant government and non-government organizations, private group and the project documents like the project terminal report, this particular experience capitalization has established that the project, making its base in the constructed/renovated drop-in/social center, provided diverse social and capacity building services for targeted OVC and their families living in Kebele 02, kebele 06 and 04 of Dire Dawa administration.

d. Therefore, ECC-SDCOH's project has:-

1. improved the psychological, social and economic situation of targeted OVC through the delivery and provision of social and capacity building services;

2. empowered and strengthened the institutional capacity of the community and their social structures in the city administration and capacitate them to address the problem of OVC while providing social and capacity building services;

3. advocated and able to lobby with government organizations, NGOs and communities, on CRC and community based prevention and rehabilitation supports to OVC and

4. improved the income of families of the targeted children by providing credit services (revolving fund scheme) for income generating activities and build their economic capacity.

\section{Recommendations}

a. Any project should create awareness on the overall issues of the project and the needed support and commitment to the various structure of the government to the end that every party could understand the very intention of the project.

b. Future project budget allocation should consider the number of OVC in a given localities as well as the fluctuation of item prices, as revealed in the terminal report and group discussion.

c. Given the mobile nature of street children, the project shall designed strategies and alternative options to integrate other vulnerable children in to the project and thereby help them to benefit from the project. Beside, organized support must be provided to minimize the drop out of street children from the project.

d. Strong follows up, monitoring \& evaluation and feedback system has to be adopted to guarantee the intension of the provision of credit services.

e. The project shall hire professional health workers, as a project staff, to properly provide health services and in effect, the health situation as well as the awareness of targets OVC could be improved significantly.

\section{Acknowledgment}

The study was accomplished with the assistance of many individuals and institutions. My special thanks go to Ethiopian Catholic Church - Social and Development Coordination Office of Harar (ECC-SDCOH) for financing the research project. This paper is the outcome of a collaborative effort between institutions and individuals. I would like to thank the top management of Kebele 04 Mebrat Haile Meredaja Iddir and Kebele 06 Raey Children Support Society (RCSS), community based organizations, for their genuine support and commitment in providing me relevant information. I am also thankful to key informant interviewees; members of the focus group discussion and survey respondents all of whom have provided useful information for the study. I extend special thanks to Mr. Tewodros Amare and Tafesse, most valuable experts in ECC-SDCOH, for their relentless commitment in reviewing the manuscript and providing valuable input and insight to improve it as well as for their assistance in editing 
the final report.

\section{References}

[1] Community Based OVC (Street Children) Prevention and Rehabilitation Project of Dire DawaTown 2007 - 2010.

[2] Community Based OVC (Street Children) Prevention and Rehabilitation Project of DireDawa Town 2012-2014.

[3] ECC - SDCOH strategic plan for Social Rehabilitation, 2002.

[4] Good Practices at FAO: Experience capitalization for continuous learning, External Concept note September, 2013.

[5] Orphan \& Vulnerable Children Prevention and Rehabilitation Project Terminal Report (March, 2007-December, 2010).
[6] Orphan \& Vulnerable Children Prevention and Rehabilitation Project Terminal Report (2012-2014) Kebele 04 Orphan \& Vulnerable Children Support Project.

[7] Plan for Accelerated and Sustained Development to End Poverty (PASDEP) document, in Ethiopia.

[8] Population and Development Indicators, Bureau of Finance and Economic Development Policy Study Plan and Development Co-operation, November, 2010.

[9] Pro pride Dire Dawa program Regional Data Base, the number of OVC in Dire Dawa, November, 2010.

[10] Standard Service Delivery Guide Lines for Orphan and Vulnerable Children's Care and Support Programs, Federal Democratic Republic of Ethiopia ministry of Health and Federal HIV/AIDS Prevention and Control Office, February, 2010. 